J Urol. 2017 March ; 197(3 Pt 1): 805-810. doi:10.1016/j.juro.2016.09.119.

\title{
Utility Estimation for Pediatric Vesicoureteral Reflux: Methodological Considerations Using an Online Survey Platform
}

\author{
Rohit Tejwani, MS ${ }^{1}$, Hsin-Hsiao S. Wang, MD, MPH ${ }^{1}$, Jessica C. Lloyd, MD¹, Paul J. \\ Kokorowski, MD, MPH ${ }^{2}$, Caleb P. Nelson, MD, MPH ${ }^{3}$, and Jonathan C. Routh, MD, MPH ${ }^{1}$ \\ ${ }^{1}$ Division of Urologic Surgery, Duke University Medical Center, Durham, NC \\ 2Division of Pediatric Urology, Children's Hospital Los Angeles \\ ${ }^{3}$ Department of Urology, Boston Children's Hospital, Boston, MA
}

\begin{abstract}
BACKGROUND-The advent of online task-distribution has opened a new avenue to efficiently gather community perspectives needed for utility estimation. Methodological consensus for estimating pediatric utilities is lacking, with disagreement over whom to sample, what perspective (patient vs. parent), and whether instrument-induced anchoring bias is significant. We sought to determine what methodological factors potentially impact utility estimates for vesicoureteral reflux (VUR).
\end{abstract}

DESIGN-Cross-sectional surveys using a time-trade-off (TTO) instrument were conducted via Amazon's Mechanical Turk online interface; respondents were randomized to answer questions from child, parent, or dyad perspectives on the utility of a VUR health state and one of three "warm-up" scenarios (paralysis, common cold, none) prior to a VUR scenario. Utility estimates and potential predictors were fitted to a generalized linear model to determine what factors most impacted utilities.

RESULTS-A total of 1,627 responses were obtained. Mean respondent age was 34.9 years; $48 \%$ were female; $38 \%$ were married; and $44 \%$ had children. Utility values were uninfluenced by child/ personal VUR/UTI history, income, or race. Utilities were affected by perspective, and were higher in the child group ( $34 \%$ lower in parent v. child, $\mathrm{p}<0.001 ; 13 \%$ lower in dyad v. child, $\mathrm{p}<0.001)$. VUR utility was not significantly affected by the presence or type of TTO warm-up scenario $(\mathrm{p}=0.17)$.

CONCLUSIONS-TTO perspective affects utilities when estimated via an online interface, however, utilities are unaffected by the presence, type, or absence of warm-up scenarios. These

Corresponding Author: Jonathan C. Routh, Division of Urologic Surgery, Duke University Medical Center, DUMC 3831, Durham, NC 27710, TEL: 919-684-6994, FAX: 919-681-5507, Jonathan.Routh@ duke.edu.

Publisher's Disclaimer: This is a PDF file of an unedited manuscript that has been accepted for publication. As a service to our customers we are providing this early version of the manuscript. The manuscript will undergo copyediting, typesetting, and review of the resulting proof before it is published in its final citable form. Please note that during the production process errors may be discovered which could affect the content, and all legal disclaimers that apply to the journal pertain.

Conflict of Interest: The authors have no relevant financial relationships to the article to disclose.

Presented at 2016 Society for Pediatric Urology meeting, San Diego, CA 
findings could have significant methodological implications for future utility elicitations in other pediatric conditions.

\section{Keywords}

Pediatric; Vesicoureteral reflux; utility

\section{INTRODUCTION}

Vesicoureteral reflux (VUR) is among the most frequently encountered conditions in pediatric urologic practice, affecting up to $70 \%$ of children who present with febrile UTI and approximately $1 \%$ of all children in the United States. ${ }^{1}$ As understanding of VUR continues to evolve, consensus remains elusive on how best to manage this condition. ${ }^{23}$

Determining optimal treatment pathways for conditions with multiple divergent management options such as VUR can be challenging for providers and families alike. Cost-utility analyses (CUA) provide relative value comparisons and can guide clinical decisionmaking. ${ }^{4,5}$ However, CUA requires condition-specific "utility" values - numerical representations of the impact of health-states or diseases on health-related quality of life (HRQoL). ${ }^{4} 6$ Utilities are numerically represented on a scale of 0 (HRQoL equal to death) to 1 (perfect health); as such, the HRQoL of a condition with a utility of 0.5 is assumed to be exactly half that of a condition with a utility of 1 . Similarly, more severe conditions with greater impact on aspects of daily living are more likely to have utility values nearer 0 than minor conditions with less impairment.

Typically estimated via direct interviews with members of the general public, or indirectly via conversion from HRQoL instruments, utility value estimates are time, cost, and resourceintensive. Pediatric utility estimation is additionally complex given the dependency of children on their caregivers and the attachment required of caregivers caring for a sick child. ${ }^{7}$ As such, the impact of a particular health-state is not only felt by the child, but also by families. ${ }^{8}$ Whether parents, affected children, or both should form the basis for utility estimation is unclear, and it is unknown to what degree existing utility methodologies truly capture accurate estimates of health-state utilities in children. Given these challenges, it is unsurprising that utility values - and, by extension, CUAs - are scarce for pediatric conditions. ${ }^{6,9}$

We have previously estimated the utility of pediatric VUR health states via online and traditional methods with comparable results, demonstrating the potential for use of such platforms in urologic research. ${ }^{10,11}$ Despite growing use of online utility estimation, standardized methodologies for such approaches remain elusive. To identify considerations for approaching utility estimation online, we sought to identify potential sources of bias inherent in online utility instruments. In particular, to determine how disease point-of-view affects pediatric utilities given aforementioned HRQoL spillover effects, and whether attempts to educate survey participants about utility estimation via "practice" or "warm-up" scenarios may inadvertently introduce degrees of anchoring bias, hypothesizing that both would significantly alter estimates of VUR utility. 


\section{PATIENTS \& METHODS}

\section{Study Design}

Cross-sectional survey studies were conducted amongst the general public to elicit utility values for VUR. Survey instruments varied either in time-trade perspective (patient, parent, or dyad of patient and parent) with consistent paraplegia warm-up scenario, or varied warmup scenario (paraplegia, common cold, or blank/no-scenario) with consistent dyad perspective. A time-trade off (TTO) approach was used to determine all utility values.

\section{Study Participants}

We used Amazon.com's 'Mechanical Turk' (AMT, www.mturk.com) online survey environment to recruit study participants. This platform serves as a crowdsourcing digital marketplace, allowing ready access to a large, stable, and diverse sample of American adults. ${ }^{12,13}$ AMT users voluntarily register to complete various "human intelligence" tasks. Each worker is assigned an ID/tracking number, preventing task repetition.

Participation in AMT tasks is typically compensated at a rate of $\$ 0.05-\$ 1.00$ for a task requiring 5-30 minutes to complete. Estimating that our survey would take 20-30 minutes to complete, we set our payment at $\$ 1.00$. Because all payments were made through an intermediary (Amazon.com), participants remained strictly anonymous. Exclusion criteria included residence outside the United States, age <18 years, and lack of English fluency. As utility values are calculated based on the perspectives of the community at-large rather than only those affected by a condition, participants were included even if they were unfamiliar with VUR, did not have children, or were not married.

\section{Instrument Development}

Participants first completed a TTO model related to an easily-understood, non-urologic health state for familiarization with TTO format and conventions, as participants were assumed to have no background or prior experience with this type of instrument.

Respondents in the perspective-variable group were introduced to TTO via a paraplegia scenario, whereas respondents in the warm-up-variable group were randomized to encounter a paraplegia, common cold, or blank/no-warm-up scenario. Participants were instructed to assume they were the parent of a hypothetical 6 year-old child affected by the health state in question, and to include the value of "preventing the pain, suffering, inconvenience, and lost time for productive activities (like school, work, and household chores) and leisure" when evaluating TTO propositions.

Subsequently, all participants were introduced to VUR via a 4-minute video (Appendix 2). A text vignette describing VUR was also presented. Participants were then presented with the VUR-based clinical scenarios and TTO utility elicitation questions based on a hypothetical 6-year-old VUR patient. The content of the health state descriptions was compiled based on: 1) interviews with patients and families affected by VUR, 2) review of the literature, and 3) expert opinion. Health states were designed to reflect typical disease courses for VUR in a child with moderately severe reflux. 
Participants in the perspective-variable cohort were randomized into three groups - child, parent, or dyad. Group allocation determined the context of TTO questions posed to the respondent (Appendix 1). Child-group respondents were asked to consider time-trades from the life of their hypothetical, affected 6 year-old child in exchange for the child spending time in a disease-free state. Parent-group respondents considered trades from their own lives to benefit their child. Similarly, questions posed to dyad-group respondents involved combined trades from both the parent's and child's lives.

Participants in the warm-up-variable group were asked to exclusively consider time trades from a dyadic perspective.

\section{Utility elicitation}

A 10-year timeframe was used for both practice and experimental scenarios, with the respondent offered a variable amount of time spent in 'perfect health' compared to 10 years in the disease state, in exchange for hypothetical trades of fixed amounts of time from their overall lifespan. Health durations changed in 1 year intervals for responses from 1 to 9 year TTO, and could be narrowed to between 0-365 days for respondents willing to trade less than one year's time. This process allows only utilities between 0 and 1 , since negative utility values are not possible with this experimental design.

We collected respondent demographics including age, gender, marital status, parental status, race/ethnicity, education achievement, annual income, and prior VUR or TTO related knowledge. Given our hypothesis that previous experience with VUR or other chronic health conditions might affect an individual's preferences for given health states, we also collected data on the health of respondents and their families.

Prior to release, each survey instrument was internally validated using a convenience sample of medical students and residents, none of whom had a personal or family history of VUR or previous experience with TTO models.

This study was reviewed by our Institutional Review board and deemed to not be human subject research. No formal consent process was thus required, though the principles of the Declaration of Helsinki were followed.

\section{Statistical Analysis}

Mean (+/- Standard Deviation (SD)) utility values and descriptive statistics were calculated. Our sample size calculation confirmed that at least 500 patients would be required to give a representative sample of the US population with a margin of error of \pm 5 percentage points. Multivariate generalized linear model was fitted to determine what factors most impacted utility estimates. Independent variables were selected according to a priori knowledge or $\mathrm{p}$ value of 0.2 on bivariate analysis.

An alpha of 0.05 and $95 \%$ confidence intervals (CI) were used as criteria for statistical significance. All analyses were performed using SAS 9.4 (SAS Institute, Cary, NC). 


\section{RESULTS}

\section{Characteristics of Study Sample}

1,852 AMT workers voluntarily participated in the surveys with 1,627 completing the task (87.9\% response rate, Table 1). Mean respondent age was 34.9 years; $48 \%$ were female. A plurality $(623,38 \%)$ was married; 708 (44\%) had children. Most were Caucasian $(1,361$, $84 \%$ ) and $41 \%$ reported completing a 4-year college degree or higher. Most respondents reported limited-or-no knowledge of VUR $(1,444,89 \%)$ or of CUA $(1,204,74 \%)$. By contrast, respondents reported a higher rate of experience with UTI (personal: 433, 27\%; family/relative: $464,29 \%$ )

Of the perspective-variable cohort (873 total), we randomly assigned 307 to the child perspective, 284 to the parent perspective, and 282 to the combined parent-child dyad perspective.

Of the warm-up-variable cohort (753 total), we randomly assigned 258 to the paraplegia scenario, 255 to common cold, and 240 to bypass the warm-up altogether.

\section{Utilities by Health State Perspective}

No respondent characteristics except for utility perspective were found to be associated with VUR utility on bivariate analysis. Multivariate analysis (Table 2) demonstrated VUR utility estimated from the parent-perspective group was $34.21 \%$ lower than utility estimated from the child-perspective $(\mathrm{p}<0.001)$; and was $13.16 \%$ lower in the dyad-perspective group versus child-perspective $(\mathrm{p}<0.001)$. Utility was found to be higher amongst single respondents ( 0.07 higher in single vs. married, $\mathrm{p}=0.007)$, and among older respondents $(0.03$ increment per 10-year age difference, $\mathrm{p}=0.008$ ). Estimated utility values of the paraplegia warm-up scenario completed by respondents in this cohort were found to follow a similar pattern (parent:child utility: $-44.44 \%$; dyad:child utility: $-17.46 \%$; $<<0.001$ ).

\section{Utilities by Warm-up Scenario}

VUR utilities were similar $(\mathrm{p}=0.17)$ in the paralysis $(0.868)$, common cold $(0.877)$, and blank/no-warm-up (0.871) groups. After adjusting for previous experience with VUR (present in either a child or a friend/relation), ethnicity, and race, VUR utility was still not significantly affected $(\mathrm{p}=0.87)$ by the presence or type of warm-up scenario (Table 3 ).

\section{DISCUSSION}

Utility theory has found significant applications in healthcare and clinical research. ${ }^{4,14,15}$ Requisite health-state utility estimates needed for CUA require considerable financial and time investments to obtain, particularly via traditional TTO methods. Internet-based estimation provides a promising opportunity to bypass these barriers.

We sought to identify potential methodological considerations for researchers considering the use of these platforms for utility estimation in pediatric urology. Our analysis revealed two important findings: that time-trade perspective significantly affects estimates of health- 
state utility, and that anchoring bias does not seem to be a factor in use of warm-up/ familiarization scenarios in VUR instruments.

A perspective-dependent VUR utility was noted despite identical VUR health states being queried. Utilities were lowest when caregivers made time trades from their own lives, intermediate when time was traded from both the caregiver's and child's life, and highest when traded exclusively from the child's life, suggesting respondents' perceptions of HRQoL impact are not only influenced by the physical effects of a condition but by external factors as well. Critically, utilities may not only be disease-specific, but perspective specific as well - a difference which may propagate through CUAs in which they are used, thereby reducing the trustworthiness of such analyses for medical decision-making.

Our findings lend credence to an intuitive assumption that parents and caregivers disparately consider trade-offs in exchange for their child's benefit. Likely multifactorial, this observation may stem from perspective-dependent variation in respondent risk aversion. ${ }^{7,} 16-18$ As noted by Hellinger and colleagues, individuals generally display reluctance to take significant risks during healthcare decision-making, with TTO methods particularly sensitive to this phenomenon. ${ }^{18}$ Consequently, such methods may inadvertently underestimate HRQoL impact, thereby overestimating health-state utility. Risk aversion is even more pronounced when considering pediatric conditions, given the roles of emotional attachment and parental/familial altruism inherent in such situations. ${ }^{7,}{ }^{19-21}$ Studies in other pediatric surgical subspecialties have demonstrated risk aversion behavior amongst parents considering surgical treatment for their children. ${ }^{20,22}$ Despite their fervent desire for positive outcomes, parents and other adults display reluctance to consent children for risky or invasive therapies, preferring safer options if available even if less efficacious. It is reasonable to assume this differential would similarly persist when respondents consider hypothetical pediatric TTO scenarios.

Pediatric utilities may further be influenced by emotional, financial, and other strain placed on caregivers and families caring for a sick dependent child. Described by Prosser and colleagues as so-called 'spillover' effects on HRQoL, such consideration may account for a degree of the perspective-dependent utility differential observed. ${ }^{8}$ This finding would seem applicable to other fields where proxy respondents must consider treatment effects both within their own and their ward's utility, such as geriatrics.

Surprisingly, anchoring effects - whereby exposure to one set of information cognitively biases an individual's perception of a subsequent set of information - were not associated with use of warm-up scenarios in our study. As noted by Paine et al, literature regarding anchoring phenomenon in patient preference assessment is conflicting and incomplete. ${ }^{23} \mathrm{We}$ are reassured that online utility estimation appears unaffected by this phenomenon given consistent VUR utilities reported after exposure to information about conditions with both severe and minimal HRQoL impact. ${ }^{10,11}$ Such exercises are generally assumed to be useful for providing necessary education on otherwise-obscure concepts associated with TTO and utility theory; particularly in the virtual environment where lack of direct interaction limits researchers' abilities to directly answer respondent questions related to experimental design 
and procedures. Interestingly, however, VUR utility was also unaffected when respondents were not exposed to any warm-up scenario at all, raising questions about this assumption.

Multiple authors have previously demonstrated comparable results from AMT sample populations to those gathered via traditional methods for utilities research. ${ }^{10,13,24-26}$ This platform, however, is not without limitations. However, gathering a truly representative sample population in a cost and time-effective manner has long been a particular challenge in utilities research. ${ }^{27}$ Prior studies have found the AMT population to be more diverse and nationally-representative than those from other widely used convenience samples, such as US undergraduates, though not as representative as other (and costlier) online probability samples. ${ }^{12,13,26}$

Additional limitations must also be considered when interpreting our study results. As mentioned, in the absence of direct interviews we were unable to query respondents for further explanation of their decisions. Thus, we can only speculate about their reasoning and its ultimate impact on utility estimation. Our study design restricted participation to respondents over the age of 18 . However, we intentionally did not restrict respondents to only those who are/were parents, nor to those familiar with VUR. Indeed, a slight majority of respondents in our study (56\%) described themselves as childless. Though it is reasonable to question whether this had an impact on utility values when asking about a pediatric condition, literature supports the use of diverse, non-affected individuals in gathering utility data to prevent over-inflation of utility scores. ${ }^{6}$ Furthermore, we observed no significant difference in mean utility scores from parents $(\mathrm{p}=0.33$ ). Lastly, use of a 10-year time frame for VUR TTO is somewhat inconsistent with the condition's generally benign, but prolonged, clinical course. However, such a time frame has been previously used by other authors for other indolent conditions. ${ }^{4,11,28}$

\section{CONCLUSION}

The utility of VUR in children is consistently highest when a child perspective is used and lowest when a parent perspective is used for elicitation. A combined parent-child dyad consistently provides a mid-range value between these two extremes. Warm-up exercises appear to have little effect on utility estimation for our condition of interest.

\section{Supplementary Material}

Refer to Web version on PubMed Central for supplementary material.

\section{Acknowledgments}

Funding Source: Financial support for this study was supported by grants K08-DK100534 (PI: Routh) and K23DK088943 (PI: Nelson) from the National Institute of Diabetes and Digestive and Kidney Diseases (NIDDK). The funding agreement ensured the authors' independence in designing the study, interpreting the data, writing, and publishing the report.

\section{REFERENCES}

1. Pohl HG, Joyce GF, Wise M, et al. Vesicoureteral Reflux and Ureteroceles. The Journal of Urology. 2007; 177:1659. [PubMed: 17437779] 
2. Heidenreich A, Ozgur E, Becker T, et al. Surgical management of vesicoureteral reflux in pediatric patients. World J Urol. 2004; 22:96. [PubMed: 15221260]

3. Routh JC, Bogaert GA, Kaefer M, et al. Vesicoureteral reflux: current trends in diagnosis, screening, and treatment. Eur Urol. 2012; 61:773. [PubMed: 22264440]

4. Prosser LA, Hammitt JK, Keren R. Measuring health preferences for use in cost-utility and costbenefit analyses of interventions in children: theoretical and methodological considerations. Pharmacoeconomics. 2007; 25:713. [PubMed: 17803331]

5. Benoit RM, Peele PB, Cannon GM Jr, et al. The cost-effectiveness of dextranomer/hyaluronic acid copolymer for the management of vesicoureteral reflux. 2. Reflux correction at the time of diagnosis as a substitute for traditional management. J Urol. 2006; 176:2649. [PubMed: 17085183]

6. Matza LS, Swensen AR, Flood EM, et al. Assessment of health-related quality of life in children: a review of conceptual, methodological, and regulatory issues. Value Health. 2004; 7:79. [PubMed: 14720133]

7. Matza LS, Boye KS, Feeny DH, et al. Impact of caregiver and parenting status on time trade-off and standard gamble utility scores for health state descriptions. Health Qual Life Outcomes. 2014; 12:48. [PubMed: 24716709]

8. Prosser LA, Lamarand K, Gebremariam A, et al. Measuring family HRQoL spillover effects using direct health utility assessment. Med Decis Making. 2015; 35:81. [PubMed: 25057048]

9. Prosser LA. Current challenges and future research in measuring preferences for pediatric health outcomes. J Pediatr. 2009; 155:7. [PubMed: 19559288]

10. Lloyd JC, Yen T, Pietrobon R, et al. Estimating utility values for vesicoureteral reflux in the general public using an online tool. J Pediatr Urol. 2014; 10:1026. [PubMed: 24766856]

11. Nelson CP, Routh JC, Logvinenko T, et al. Utility scores for vesicoureteral reflux and anti-reflux surgery. J Pediatr Urol. 2015

12. Briones EM, Benham G. An examination of the equivalency of self-report measures obtained from crowdsourced versus undergraduate student samples. Behav Res Methods. 2016

13. Amir O, Rand DG, Gal YK. Economic games on the internet: the effect of \$1 stakes. PLoS One. 2012; 7:e31461. [PubMed: 22363651]

14. Carroll AE, Downs SM. Improving decision analyses: parent preferences (utility values) for pediatric health outcomes. J Pediatr. 2009; 155:21. [PubMed: 19394030]

15. Hsieh MH, Swana HS, Baskin LS, et al. Cost-utility analysis of treatment algorithms for moderate grade vesicoureteral reflux using Markov models. J Urol. 2007; 177:703. [PubMed: 17222660]

16. Bleichrodt $\mathrm{H}$. A new explanation for the difference between time trade-off utilities and standard gamble utilities. Health Econ. 2002; 11:447. [PubMed: 12112493]

17. Groll D. Four models of family interests. Pediatrics. 2014; 134(Suppl 2):S81. [PubMed: 25274879]

18. Hellinger FJ. Expected utility theory and risky choices with health outcomes. Med Care. 1989; 27:273. [PubMed: 2927183]

19. Lipstein EA, Britto MT. Evolution of Pediatric Chronic Disease Treatment Decisions: A Qualitative, Longitudinal View of Parents' Decision-Making Process. Med Decis Making. 2015

20. Stasio SD, Yang C, Brietzke SE, et al. Tonsillectomy versus tonsillotomy: a study of parental preference. Int J Pediatr Otorhinolaryngol. 2015; 79:359. [PubMed: 25604258]

21. Wittenberg E, Prosser LA. Disutility of illness for caregivers and families: a systematic review of the literature. Pharmacoeconomics. 2013; 31:489. [PubMed: 23572441]

22. Brody JL, Annett RD, Scherer DG, et al. Comparisons of adolescent and parent willingness to participate in minimal and above-minimal risk pediatric asthma research protocols. J Adolesc Health. 2005; 37:229. [PubMed: 16109343]

23. Paine AM, Allen LA, Thompson JS, et al. Anchoring in Destination Therapy Left Ventricular Assist Device Decision Making: A Mechanical Turk Survey. J Card Fail. 2016

24. Simons DJ, Chabris CF. Common (mis)beliefs about memory: a replication and comparison of telephone and Mechanical Turk survey methods. PLoS One. 2012; 7:e51876. [PubMed: 23272183]

25. Sprouse J. A validation of Amazon Mechanical Turk for the collection of acceptability judgments in linguistic theory. Behav Res Methods. 2011; 43:155. [PubMed: 21287108] 
26. Buhrmester M, Kwang T, Gosling SD. Amazon's Mechanical Turk: A New Source of Inexpensive, Yet High-Quality, Data? Perspect Psychol Sci. 2011; 6:3. [PubMed: 26162106]

27. Gold, MR., Siegel, JE., Russell, LB., et al. Cost-effectiveness in Health and Medicine. New York: Oxford University Press; 1996.

28. Matza LS, Sapra SJ, Dillon JF, et al. Health state utilities associated with attributes of treatments for hepatitis C. Eur J Health Econ. 2014

\section{Abbreviations Used}

VUR Vesicoureteral Reflux

HRQoL Health-Related Quality of Life

AMT Amazon.com Mechanical Turk (MTurk)

UTI Urinary Tract Infection

TTO Time Trade Off 
Table 1

Respondent Demographics by Perspective Group

\begin{tabular}{|c|c|c|c|}
\hline & $\begin{array}{c}\text { Perspective-Variable Group } \\
(\mathbf{n}=\mathbf{8 7 3})\end{array}$ & $\begin{array}{c}\text { Warm-up-Variable Group } \\
(\mathbf{n}=\mathbf{7 5 3})\end{array}$ & $\begin{array}{l}\text { Total }(\%) \\
(n=1627)\end{array}$ \\
\hline Age (Mean, SD) & $34.4(11.1)$ & $35.8(11.5)$ & $34.9(11.3)$ \\
\hline \multicolumn{4}{|l|}{ Gender } \\
\hline Male & $462(53 \%)$ & $385(51 \%)$ & $846(52 \%)$ \\
\hline Female & $408(47 \%)$ & $369(49 \%)$ & $777(48 \%)$ \\
\hline \multicolumn{4}{|l|}{ Marital status } \\
\hline Single & $408(47 \%)$ & $298(40 \%)$ & $706(43 \%)$ \\
\hline Married & $299(34 \%)$ & $324(43 \%)$ & $623(38 \%)$ \\
\hline Separated/Divorced & $62(7.1 \%)$ & $48(6.4 \%)$ & $109(7 \%)$ \\
\hline Widowed & $5(0.5 \%)$ & $6(0.8 \%)$ & $11(1 \%)$ \\
\hline Living with Partner & $98(11 \%)$ & $78(10 \%)$ & $176(11 \%)$ \\
\hline \multicolumn{4}{|l|}{ Children } \\
\hline Yes & $340(39 \%)$ & $369(49 \%)$ & $708(44 \%)$ \\
\hline No & $531(61 \%)$ & $385(51 \%)$ & $916(56 \%)$ \\
\hline \multicolumn{4}{|l|}{ VUR knowledge } \\
\hline Never heard of it & $680(78 \%)$ & $535(71 \%)$ & $1141(70 \%)$ \\
\hline May have heard of it, but not sure & $156(18 \%)$ & $174(23 \%)$ & $303(19 \%)$ \\
\hline Concept but not details & $30(3.4 \%)$ & $77(10 \%)$ & $135(8 \%)$ \\
\hline Pretty good understanding & $5(0.5 \%)$ & $36(4.8 \%)$ & $38(2 \%)$ \\
\hline Ample knowledge & $2(0.1 \%)$ & $8(1.1 \%)$ & $9(0 \%)$ \\
\hline \multicolumn{4}{|l|}{ UTI knowledge } \\
\hline Never heard of it & $15(1.7 \%)$ & $26(3.5 \%)$ & $38(2 \%)$ \\
\hline May have heard of it, but not sure & $52(5.9 \%)$ & $56(7.4 \%)$ & $102(6 \%)$ \\
\hline Concept but not details & $452(52 \%)$ & $314(42 \%)$ & $717(44 \%)$ \\
\hline Pretty good understanding & $297(34 \%)$ & $350(47 \%)$ & $609(37 \%)$ \\
\hline Ample knowledge & $57(6.5 \%)$ & $116(15 \%)$ & $160(10 \%)$ \\
\hline \multicolumn{4}{|l|}{ CUA knowledge } \\
\hline Never heard of it & $399(46 \% 0$ & $315(42 \%)$ & $657(40 \%)$ \\
\hline May have heard of it, but not sure & $308(35 \%)$ & $258(34 \%)$ & $547(34 \%)$ \\
\hline Concept but not details & $125(14 \%)$ & $209(28 \%)$ & $311(19 \%)$ \\
\hline Pretty good understanding & $34(4 \%)$ & $60(8.0 \%)$ & $90(6 \%)$ \\
\hline Ample knowledge & $7(0.8 \%)$ & $15(2.0 \%)$ & $27(1 \%)$ \\
\hline VUR history (self) & $2(0.2 \%)$ & $33(4.4 \%)$ & $35(1 \%)$ \\
\hline UTI history (self) & $227(26 \%)$ & $206(27 \%)$ & $433(27 \%)$ \\
\hline VUR history (child) & $19(2.2 \%)$ & $47(6.2 \%)$ & $27(2 \%)$ \\
\hline UTI history (child) & $19(2.2 \%)$ & $47(6.2 \%)$ & $66(4 \%)$ \\
\hline VUR history (relative) & $3(0.3 \%)$ & $35(4.6 \%)$ & $39(2 \%)$ \\
\hline
\end{tabular}

J Urol. Author manuscript; available in PMC 2018 March 01. 


\begin{tabular}{|c|c|c|c|}
\hline & $\begin{array}{c}\text { Perspective-Variable Group } \\
(\mathrm{n}=\mathbf{8 7 3})\end{array}$ & $\begin{array}{c}\text { Warm-up-Variable Group } \\
(\mathbf{n}=\mathbf{7 5 3})\end{array}$ & $\begin{array}{l}\text { Total }(\%) \\
(n=1627)\end{array}$ \\
\hline UTI history (relative) & $195(22 \%)$ & $203(27 \%)$ & $398(24 \%)$ \\
\hline \multicolumn{4}{|l|}{ Education } \\
\hline Less than high school & $7(0.8 \%)$ & $8(1.1 \%)$ & $15(1 \%)$ \\
\hline High school diploma or GED & $118(14 \%)$ & $65(8.6 \%)$ & $184(11 \%)$ \\
\hline Some college & $256(36 \%)$ & $186(25 \% 0$ & $442(27 \%)$ \\
\hline 2-year college degree & $112(13 \%)$ & $79(11 \%)$ & $191(12 \%)$ \\
\hline 4-year college degree & $311(36 \%)$ & $314(42 \% 0$ & $625(38 \%)$ \\
\hline Masters degree & $52(6.0 \%)$ & $87(12 \%)$ & $139(9 \%)$ \\
\hline Doctoral/professional degree & $17(1.9 \%)$ & $14(1.9 \%)$ & $31(2 \%)$ \\
\hline \multicolumn{4}{|l|}{ Income } \\
\hline Less than $\$ 20,000$ & $164(19 \%)$ & $103(14 \%)$ & $307(19 \%)$ \\
\hline$\$ 20,000-\$ 49,000$ & $405(46 \%)$ & $321(43 \%)$ & $726(45 \%)$ \\
\hline$\$ 50,000-\$ 89,000$ & $208(24 \%)$ & $419(56 \%)$ & $419(26 \%)$ \\
\hline$\$ 90,000$ or greater & $96(11 \%)$ & $78(10 \%)$ & $174(11 \%)$ \\
\hline \multicolumn{4}{|l|}{ Race } \\
\hline White & $725(83 \%)$ & $537(71 \%)$ & $1361(84 \%)$ \\
\hline Black & $55(6.3 \%)$ & $54(7.2 \%)$ & $199(7 \%)$ \\
\hline Other & $108(12 \%)$ & $163(22 \%)$ & $257(16 \%)$ \\
\hline
\end{tabular}


Table 2

Multivariate Analysis of Demographic Variables vs. Perspective-dependent VUR Utility

\begin{tabular}{|c|c|c|}
\hline Respondent Characteristics & Estimate & p value \\
\hline \multicolumn{3}{|l|}{ Perspectives } \\
\hline Child & reference & \\
\hline Parent & -0.27 & $<0.001$ \\
\hline dyad & -0.09 & $<0.001$ \\
\hline Age (increment of 10 years) & 0.03 & 0.008 \\
\hline \multicolumn{3}{|l|}{ Marital status } \\
\hline Single & reference & \\
\hline Married & -0.07 & 0.007 \\
\hline Separated/Divorced & -0.08 & 0.08 \\
\hline Widowed & 0.21 & 0.15 \\
\hline Living with Partner & -0.01 & 0.79 \\
\hline \multicolumn{3}{|l|}{ UTI history (self) } \\
\hline Yes & reference & \\
\hline No & -0.04 & 0.12 \\
\hline \multicolumn{3}{|l|}{ UTI history (child) } \\
\hline$\overline{\text { Yes }}$ & reference & \\
\hline No & -0.09 & 0.20 \\
\hline Income & 0.01 & 0.28 \\
\hline \multicolumn{3}{|l|}{ Race } \\
\hline White & reference & \\
\hline Black & 0.05 & 0.21 \\
\hline Other & -0.05 & 0.12 \\
\hline
\end{tabular}

